\title{
O efeito do Bolsa Família sobre a distorção idade-série
}

\author{
Jevuks Matheus Araújo ${ }^{1}$ \\ Gustavo Saraiva Frio ${ }^{2}$ \\ Pedro Jorge Holanda Alves ${ }^{3}$
}

\section{Resumo}

Em 2019, a taxa de distorção idade-série foi de 23,4\% e 26,2\% para os anos finais do ensino fundamental e do ensino médio, respectivamente. As elevadas taxas de distorção idade-série (TDI) reduzem a escolarização e elevam os custos decorrentes do atraso escolar. O objetivo desse trabalho é estimar o efeito do Programa Bolsa Família (PBF) sobre a distorção idade-série. Foram utilizados os microdados do Suplemento Educação da Pesquisa Nacional de Amostras por Domicílio Contínua, referente ao 20 Trimestre dos anos de 2016 a 2019, e a técnica utilizada foi o Propensity Score Matching (PSM). Os resultados mostraram que participar do PBF reduz entre 2,23 e 6,02 p.p. a TDI. Os efeitos são maiores para os meninos, redução entre 3,99 e 7,22 p.p., e na região Centro-Oeste, cuja redução foi de 11,1 p.p. Os resultados nos levaram a concluir que o PBF gera efeitos positivos sobre indicadores educacionais.

\section{Palavras-chave}

Distorção idade-série. PBF. educação.

\begin{abstract}
In 2019 , the age-grade distortion rate was $23.4 \%$ and $26.2 \%$ for the final years of elementary and high school, respectively. The high rates of age-grade distortion (TDI) reduce schooling and increase costs due to school delay. The objective of this work is to estimate the effect of the Bolsa Familia Program (PBF) on age-grade distortion. The microdata from the Education Supplement of the National Sample Survey by Continuous Household for the 2nd Quarter of
\end{abstract}

- O presente trabalho foi realizado com apoio da Coordenação de Aperfeiçoamento de Pessoal de Nível Superior - Brasil (CAPES) - Código de Financiamento 001.

1 Professor - Universidade Federal da Paraíba - End.: Campus I - Lot. Cidade Universitária João Pessoa -PB - Brasil - CEP: 58051-900 - E-mail: jevuks@gmail.com - ORCID:https://orcid. org/0000-0002-5618-4502.

2 Universidade de Brasília - Programa de Pós-Graduação em Saúde Coletiva - End.: Campus Universitário Darcy Ribeiro, Brasília - DF - Brasil - CEP: 70910-900 - E-mail: gustavo.frio@gmail.com. ORCID: https://orcid.org/0000-0001-6453-312X.

${ }^{3}$ Doutorando - Universidade Católica de Brasília - End.: QS 07 - Lote 01, EPCT - Taguatinga, Brasília - DF - Brasil - CEP: 71966-700 - E-mail: pedrojorge_holanda@hotmail.com - ORCID: https:// orcid.org/0000-0001-9340-030X.

Recebido: 14/12/2019. Aceito: 07/12/2020.

Editor Responsável: Dante Mendes Aldrighi

(c) (i) (\$) Esta obra está licenciada com uma Licença Creative Commons Atribuição-Não Comercial 4.0 Internacional. 
the years 2016 to 2019 were used, and the technique used was the Propensity Score Matching (PSM). The results showed that participating in the PBF reduces between the distortion 2.23 and 6.02 p.p. The effects are greater for boys, reduction between 3.99 and 7.22 p.p., and in the Midwest region, whose reduction was 11.1 p.p. The results led us to conclude that the PBF generates positive effects on educational indicators.

\section{Keywords}

Distortion age-grade. PBF. education.

\section{JEL Classification}

124, 138, D61

\section{Introdução}

Ao longo das últimas décadas, Programas de Transferência de Renda Condicionada (PTRCs) ${ }^{1}$ se tornaram importantes instrumentos de combate à pobreza no país - em especial, o Programa Bolsa Família (PBF). A favor do programa está o baixo custo de manutenção: em 2016, o Bolsa Família representou apenas $0.45 \%$ do PIB. Além do custo reduzido, há uma série de estudos que mostram os impactos desse programa nos mais diversos indicadores socioeconômicos. Ribeiro, Shikida e Hillbrecht (2017) fizeram um levantamento de mais de 50 artigos publicados que realizaram avaliação de impacto do programa Bolsa Família nas mais diversas áreas (pobreza, educação, nutrição, trabalho infantil etc.).

$\mathrm{Na}$ área específica de educação, as variáveis de resultados mais utilizadas são: frequência escolar, evasão escolar e taxa de matrícula. Na generalidade, os trabalhos aplicados (usando diferentes métodos) mostram que o programa Bolsa Família gera impactos positivos sobre essas variáveis ${ }^{2}$. A frequência escolar e a progressão das crianças beneficiárias são condições necessárias para acumulação de capital humano, mas, certamente, insuficientes. A qualidade das escolas ou dos serviços educacionais que atendem as crianças de famílias beneficiárias do PBF desempenha um papel chave, sendo um ponto importante para a discussão a respeito da complementariedade das políticas públicas direcionadas às famílias pobres.

1 Alguns estudos mostram impactos dos PTRCs na América Latina (Soares, 2010; Soares et al., 2007).

2 Ver Quadro 1 - Resumo da Literatura no apêndice A. 
O objetivo desse trabalho é estimar o impacto do PBF sobre a distorção idade-série e para a avaliação empírica será utilizado o método de Propensity Score Matching (PSM). Os dados serão extraídos a partir dos microdados da Pesquisa Nacional por Amostra de Domicílios Contínua (PNAD Contínua) do segundo trimestre dos anos de 2016, 2017, 2018 e 2019. A fim de estimar possíveis heterogeneidades dos resultados, estes serão separados por gênero, regiões e ano da pesquisa.

Dessa forma, além de estudar uma variável pouco explorada (distorção idade-série), este trabalho deverá contribuir para o avanço nas áreas inconclusivas. Ademais, como ressaltado por Ribeiro, Shikida e Hillbrecht (2017), há necessidade de mais pesquisas que avaliem possíveis diversidades regionais.

O Brasil é um país com forte heterogeneidade regional. Segundo os dados do IBGE (2019), no ano de 2017, a participação no PIB por Regiões apresentava a seguinte distribuição: $5,6 \%, 10 \%, 14,5 \%, 17 \%$ e $52,9 \%$ para as regiões Norte, Centro-Oeste, Nordeste, Sul e Sudeste, respectivamente. As desigualdades regionais são identificadas em outros indicadores econômicos e sociais, por exemplo, em 2018, foi registrado o número de $6,8 \%$ de pessoas analfabetas (com 15 anos ou mais) no Brasil. Enquanto o percentual de analfabetos na região Sudeste foi de apenas 3,43\%, na região Nordeste este número foi de $13,87 \%$. As diferenças regionais devem refletir no desempenho das políticas sociais, sendo assim, Souza (2011) mostra que o PBF possui uma melhor focalização nas regiões Norte e Nordeste do país.

Ribeiro e Cacciamali (2012) estimaram o impacto do PBF sobre a frequência escolar e a distorção idade-série usando dados da PNAD (2006) e a técnica de Propensity Score Matching (PSM) e encontraram resultados não significativos. Seus resultados chamam bastante atenção por dois motivos: primeiro, por ser, provavelmente, o único trabalho que não encontrou efeito do Bolsa Família na frequência escolar, que é um dos condicionantes do programa; segundo, pela importância da distorção idade-série no Brasil.

Segundo dados do INEP, no ano de 2016, 12 a cada 100 alunos matriculados nas escolas estavam com idade distorcida, ou seja, com dois anos ou mais de atraso; em 2006, entretanto, a taxa de distorção idade-série era de $23 \%$. Embora combater o problema da distorção idade-série não seja objetivo direto do programa, a taxa pode ser explicada por três fatores 
distintos: a entrada tardia na escola, a reprovação e a evasão; que são canais diretamente afetados pelas condicionalidades do programa.

Ressaltamos que este trabalho possui uma forte interseção com o trabalho de Ribeiro e Cacciamali (2012). Entretanto, além de revistarmos a temática para uma base de dados mais recente, destacaremos duas importantes mudanças institucionais: a primeira, diz respeito à implantação, em 2010, da Lei $n^{0} 11.274 / 06$, que estabelece o ensino fundamental com duração de 9 anos (sendo 6 anos a idade ideal de entrada); e, a segunda, é o Decreto $n^{\circ} 6.491 / 2008^{3}$, que estabelece a expansão do programa Bolsa Família com a criação do benefício variado para jovens de 16 e 17 anos regularmente matriculados em instituições de ensino.

Diferente do trabalho de Ribeiro e Cacciamali (2012), nossos resultados mostrarão que participar do Bolsa Família reduz significativamente a distorção idade-série. Com base empilhada para todos os anos, os resultados (usando 5 diferentes algoritmos de pareamento) apresentarão uma redução significativa entre 2,2pp e 6,02pp. Os resultados também salientarão uma heterogeneidade de gênero; embora o efeito tenha sido negativo e significativo para meninos e meninas, a redução estimada para os meninos foi em magnitude superior, variando entre 4,4pp e 7,2pp, enquanto para as meninas a redução variou entre 2,7pp e 4,5pp. Na análise de heterogeneidade regional serão percebidos efeitos negativos e significativos para todas as regiões, exceto para a região Sul.

O trabalho conta com cinco seções, com essa introdução. Na seção dois, será discutido o panorama brasileiro, destacando a distorção idade série e o Programa Bolsa Família no Brasil; na seção 3 apresentaremos os dados e metodologia e na seção 4 serão apresentados e discutidos os resultados. Por fim, serão apresentadas as considerações finais.

3 Substituído pelo Decreto n $5.209 / 2009$. 


\section{Panorama brasileiro}

\subsection{Distorção idade-série no Brasil}

O Ministério da Educação (MEC) é responsável por gerir o sistema educacional brasileiro, separando responsabilidades, verbas e sua estrutura. Em relação à divisão estrutural, o MEC define como 6 anos a idade adequada para o ingresso no ensino fundamental, cuja duração é de 9 anos - outrora, era indicada como 7 anos para o ensino fundamental, que tinha como duração o período de 8 anos -, e para cursar o ensino médio, a idade definida vai dos 15 aos 18 anos. Contudo, os dados do Instituto Nacional de Estudos e Pesquisas Educacionais Anísio Teixeira (INEP) mostram, em 2016, que uma proporção de $68 \%$ dos alunos matriculados na rede pública de ensino médio está com a idade correta. Para combater a evasão, o Programa Nacional da Educação (PNE) estipula metas de universalizar o atendimento escolar para toda população entre 15 e 17 anos até 2016, de forma que a taxa líquida de matrícula ${ }^{4}$ alcance a marca de $85 \%$.

A literatura vem tentando buscar resultados mais eficientes, visto que a meta não foi atingida. Em um contexto teórico, Langoni (2005) afirma que a escolha das famílias pobres de não matricular os filhos na escola está relacionada ao custo de oportunidade para o filho trabalhar. Em outras palavras, a necessidade de salário no curto prazo gera decisões de trabalho nos períodos considerados ideais para o desenvolvimento da educação.

Nesse contexto, Hanushek e Woessmann (2008) afirmam que a decisão de evadir ou não é causada pelos choques negativos de renda das famílias. Segundo os autores, melhorias na qualidade do sistema escolar e nos insumos familiares podem gerar aperfeiçoamento das habilidades cognitivas.

Esse processo de escolha pode levar ao que Myrdal (1975) definiu como ciclo vicioso da pobreza. De acordo com o Fundo das Nações Unidas para a Infância (UNICEF), para "romper o círculo vicioso da reprovação, do atraso, da distorção idade-série e do abandono" é preciso que haja um esforço conjunto de vários setores e segmentos da sociedade brasileira.

Os dados do INEP (Gráfico 1) mostram que a taxa de distorção idade-série vem caindo bastante entre 1999 e 2019, com base nisso, podemos destacar uma queda mais acentuada entre 1999 e 2008 e uma queda menos

${ }_{4}$ Número de alunos matriculados na idade certa. 
acentuada entre 2009 e 2019. De forma geral, em 1998, aproximadamente 4 a cada 10 alunos matriculados nos anos iniciais tinham 2 anos ou mais de atraso escolar; já em 2018, apenas 1 a cada 10 alunos matriculados no mesmo nível de ensino tinha 2 anos ou mais de atraso escolar.

A queda no primeiro período pode estar associada a um conjunto de políticas sociais implantadas no Brasil, como o Bolsa Escola, implantado em 2001, e o Bolsa Família, implantado em 2003; ambos trazem a frequência escolar como condição. Podemos destacar também que no período de 2004 a 2008 a economia brasileira cresceu em média 3,5\%, o que reduziu a taxa de desemprego de 14\%, em 2004, para 7.5\%, em 2008.

A política social e o bom cenário econômico devem reduzir os custos de oportunidades para as famílias matricularem os filhos na escola. No período subsequente, apesar da continuidade de redução da taxa de distorção idade-série, há uma desaceleração do ritmo de queda, principalmente, nos anos finais. A justificativa pode estar na piora do ambiente econômico, que traz instabilidade financeira às famílias mais pobres, elevando novamente os custos de oportunidade, sobretudo para os jovens na faixa etária dos anos finais do ensino fundamental e do ensino médio.

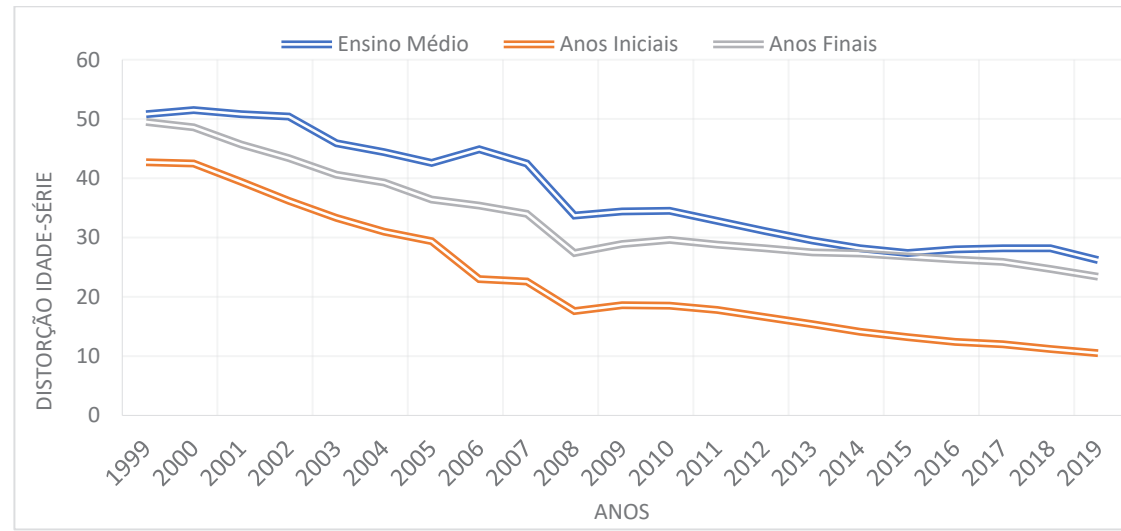

Gráfico 1 - Taxa de distorção idade-série do Brasil por nível de ensino Fonte: Elaboração própria com base nos dados do INEP. 
A evasão das crianças e adolescentes pode ser um dos principais determinantes para a ineficiência escolar. De acordo com Bissoli (2007), um aluno que abandona a escola antes de concluir uma série ou determinado nível escolar resulta em oneração dos recursos destinados ao investimento educacional.

A Figura 1 mostra a distribuição por município da taxa de distorção idade-série. Observamos que as maiores taxas de distorção se concentram nas regiões Norte e Nordeste do Brasil, que possuem, respectivamente, em média, $20,9 \%$ e $29,1 \%$ dos alunos com idade fora do ideal para o ensino fundamental e médio. Também observamos que, em todas as regiões, o problema da distorção idade-série é mais grave no ensino médio.
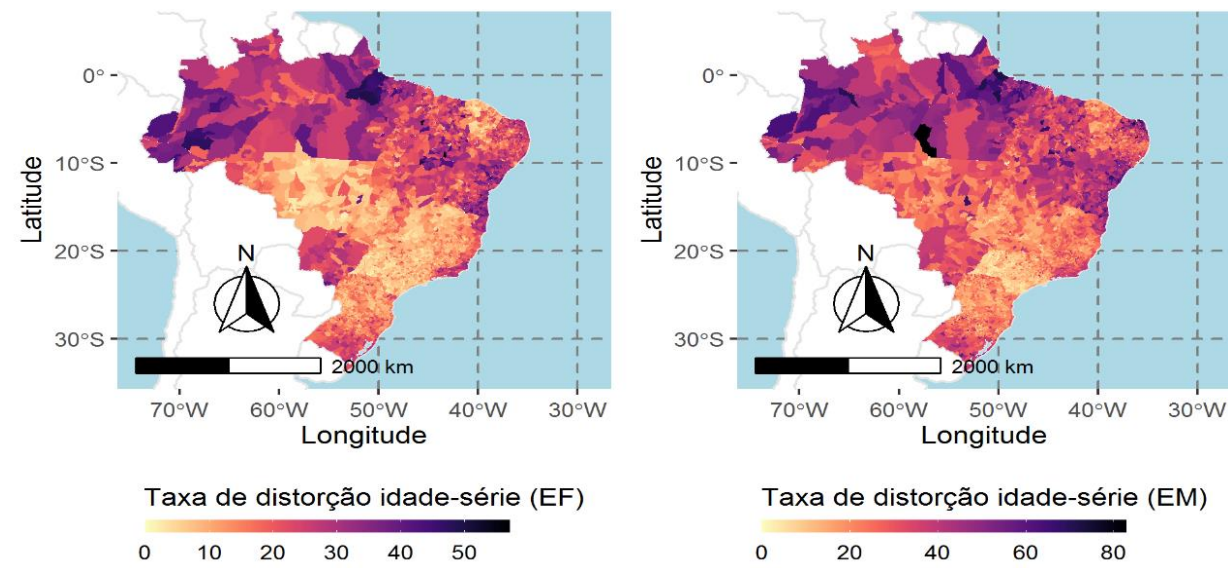

Figura 1 - Taxa de distorção idade-série em 2019

Fonte: Elaboração própria

\subsection{Programa Bolsa Família}

O Programa Bolsa Família aparece com o intuito de solucionar diversos problemas, um deles é a evasão escolar. A característica central do programa é que o recebimento dos benefícios monetários pelas famílias é atrelado ao cumprimento de algumas regras que envolvem cuidados de saúde e de educação das crianças e dos adolescentes. E o seu objetivo principal é atenuar os efeitos negativos da pobreza sobre o bem-estar no curto prazo, além de atingir determinadas exigências na educação e na saúde 
das crianças e dos adolescentes em longo prazo. Em geral, o programa tem como missão romper com a armadilha da pobreza causada, em boa parte, pela transmissão intergeracional de renda e de capital humano. ${ }^{5}$

A respeito da dimensão do $\mathrm{PBF}$ em termos de população beneficiada, em 20196 , segundo dados do Ministério do Desenvolvimento Social Secretaria de Avaliação e Gestão da Informação -, havia aproximadamente 14 milhões de pessoas contempladas pelos benefícios do programa. Parametrizando este número no total da população estimada do país, a cobertura chegava a quase $6,65 \%$ da população brasileira. Em termos monetários, em todo o ano de 2017 , o programa custou pouco mais de $\mathrm{R} \$ 32$ bilhões de reais ou algo próximo a $0,4 \%$ do PIB.

O Programa Bolsa Família foi criado no ano de 2003 com o objetivo de gerar algum tipo de renda para a população extremamente pobre, e é realizado pelo Governo Federal. O programa originou-se da união dos programas Bolsa Escola (criada em 2001), Cadastro Único do Governo Federal (2001), Bolsa Alimentação (2001), Auxílio-Gás (2002) e FomeZero (2003).

O PBF possui alguns critérios de elegibilidade, sendo os seguintes para 2019:

- Estar em situação de extrema pobreza ou pobreza, com renda per capita até $R \$ 85,00$ ou entre $R \$ 85,01$ e $R \$ 170,00$, respectivamente;

- Estar com a família inscrita e com todos os dados atualizados nos últimos 2 anos no Cadastro Único para Programas Sociais, do Governo Federal;

- No caso das gestantes, estarem com as consultas do pré-natal em dia e participarem de atividades educativas sobre aleitamento materno e educação saudável;

5 Existe uma ampla literatura sobre transmissão intergeracional de renda e de capital humano (Becker; Tomes, 1979; Ferreira; Veloso, 2003; Machado; Gonzaga, 2007; Mazumder, 2005)ability, and other characteristics, family reputation and \"connections,।" and knowledge, skills, and goals provided by their family environment. The fortunes of children are linked to their parents not only through investments but also through these endowments acquired from parents (and other family members.

6 O presente estudo não tem por objetivo apresentar o arcabouço institucional ou a história do PBF, porém existem diversos estudos sobre tais temas (Cavalcanti et al., 2016; Chitolina; Foguel; Menezes-Filho, 2016; Nascimento; Kassouf, 2016; Simões; Soares, 2012). 
- Manter o cartão de vacinação das crianças entre 0 e 17 anos em dia e o acompanhamento da saúde das mulheres entre 14 e 44 anos;

- E garantir 85\% de frequência escolar para as crianças e os adolescentes entre 6 el5 anos e 75\% para adolescentes entre 16 e 17 anos.

O Bolsa Família, desde a sua criação, realiza dois tipos de benefícios: o benefício básico, no qual pessoas em situação de extrema pobreza (renda per capita de no máximo $\mathrm{R} \$ 85,00)$ terão auxílio de $\mathrm{R} \$ 85,00$; e o benefício variável, no qual pessoas podem acumular 5 benefícios de $\mathrm{R} \$ 35$ reais (totalizando R\$ 195,00) por cada mulher gestante, amamentando ou crianças e adolescentes de 0 a 16 anos.

Com o sucesso, o PBF foi se adaptando e se aperfeiçoando ao longo dos anos. Por exemplo, os dados mostrados no Gráfico 2 apontam que o número de beneficiários saltou de 4,5 milhões pessoas, em 2004, para 13,7 milhões, em 2019. Em contrapartida, o gasto do governo saltou de aproximadamente 4 bilhões, em 2004, para aproximadamente 32 bilhões, em 2019.

O benefício médio, segundo os dados do Ministério do Desenvolvimento Social junto com o IBGE, mostra que o Bolsa Família só teve reajuste seis vezes ao longo dos anos. Em 2004, o benefício médio chegava próximo dos $\mathrm{R} \$ 80,00$, enquanto em 2016 o benefício médio foi de $\mathrm{R} \$ 176,00$.

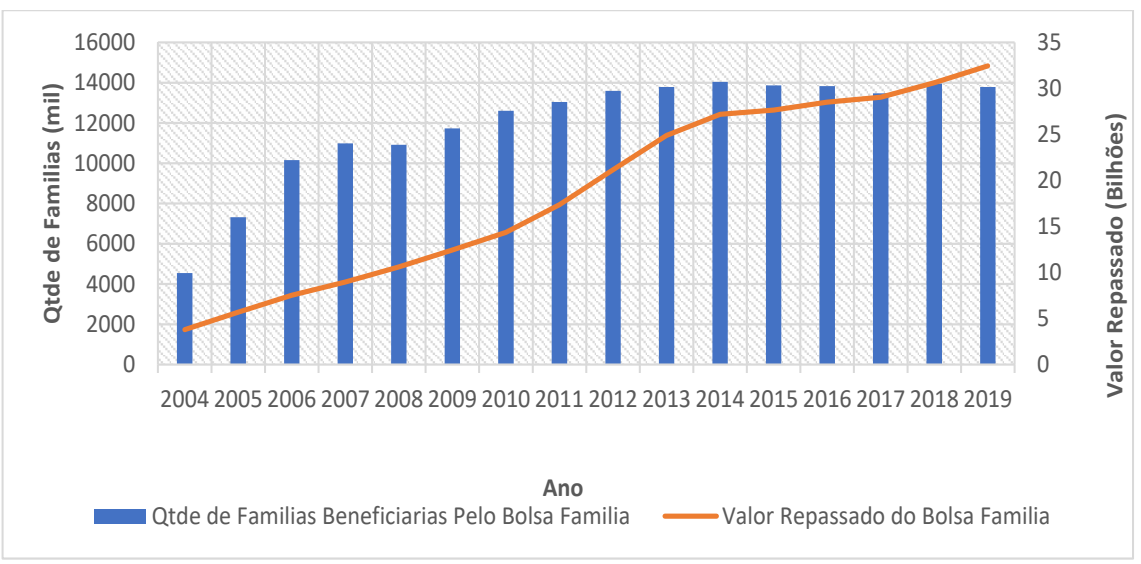

Gráfico 2 - Valor transferido e número de beneficiados do PBF (2004-2019)

Fonte: Elaboração própria com base nos dados do INEP 
Ao observar o número médio de famílias beneficiadas por município, ponderado pela população, é possível verificar que, espacialmente, a proporção de famílias se concentra no Norte e Nordeste (Figura 2). Essa observação se torna importante, uma vez que, de acordo com a Figura 1, os municípios que possuem maiores taxas de distorção idade-série são municípios das referidas regiões. Em média, entre 200 e 300 famílias a cada 1000 habitantes recebem Bolsa Família no Norte e Nordeste, enquanto nas demais regiões do Brasil essa proporção é inferior a 100 famílias.

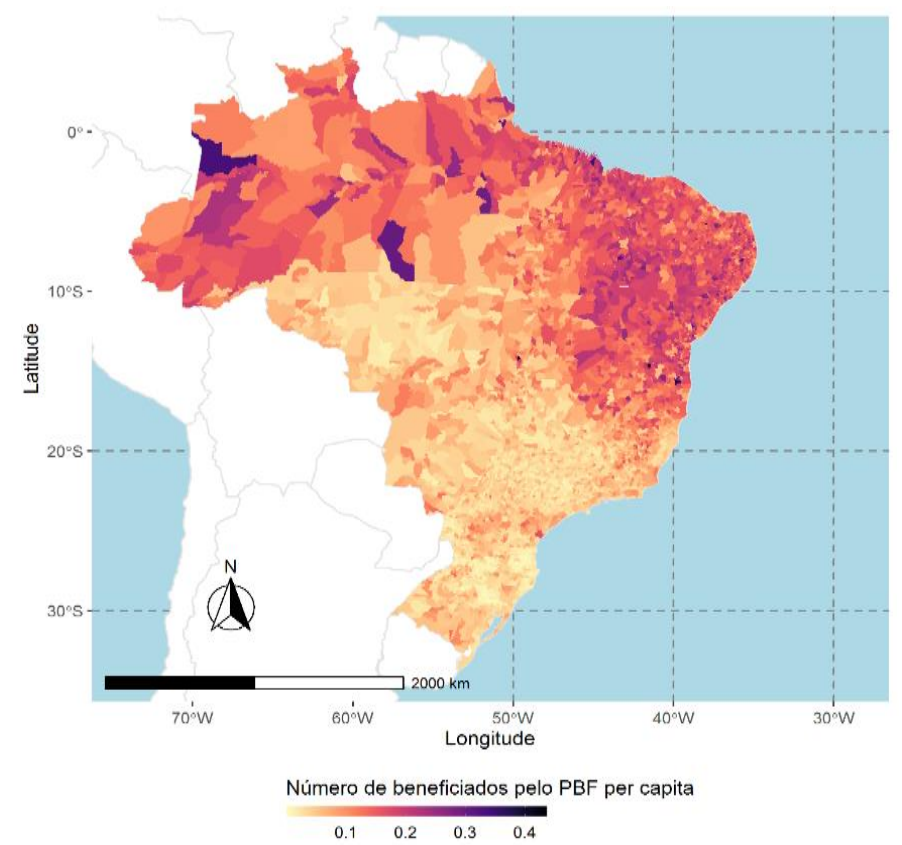

Figura 2 - Quantidade média de famílias beneficiadas pelo PBF per capita (2019) Fonte: Elaboração própria

\section{Material e métodos}

\subsection{Banco de dados}

Utilizamos os microdados do Suplemento Educação da Pesquisa Nacional de Amostras por Domicílio - PNAD Contínua com suplemento educacional - referente ao $2^{\circ}$ Trimestre entre os anos de 2016 e 2019, realiza- 
da pelo Instituto Brasileiro de Geografia e Pesquisa - IBGE. O principal objetivo da PNAD Contínua é produzir informações sobre a dinâmica do mercado de trabalho no país, sendo também agregadas características demográficas e educacionais da população. A pesquisa é realizada trimestralmente, com base em entrevistas em domicílios particulares e permanentes, e abrange cerca de 3.500 municípios brasileiros, e a divulgação dos resultados ocorre mensalmente para um conjunto restrito de indicadores agregados em nível nacional, e trimestralmente para todos os indicadores em nível regional, estadual, capitais e regiões metropolitanas.

Além das pesquisas ordinárias, é comum o IBGE investigar outros temas suplementares no âmbito da PNAD Contínua, como educação, trabalho infantil, características gerais dos domicílios, rendimentos etc. Para o segundo trimestre de 2016, 2017, 2018 e 2019, foram divulgadas estatísticas detalhadas sobre os indicadores relacionados à educação no Brasil, com a informação adicional de participação ou não no programa de Bolsa Família, base que é utilizada neste trabalho. Foram retiradas da amostra as famílias que recebiam renda familiar ex-ante - sem considerar a renda oriunda do Bolsa Família - acima do valor do programa (Cechin et al., 2015).

\subsection{Metodologia}

Nesse trabalho buscamos analisar a relação causal entre participar do Programa Bolsa Família e os efeitos na taxa de distorção idade-série. O problema central de identificação, em análise causal, é encontrar o melhor grupo de controle, uma vez que uma má especificação resulta em uma análise enviesada do verdadeiro efeito do tratamento. O cenário ideal seria poder comparar um mesmo indivíduo em duas situações distintas: recebendo o tratamento $(\mathrm{PBF})$ e não recebendo o tratamento, o que é claramente impossível de acontecer, pois as situações são mutuamente excludentes.

Entretanto, a seleção para participar do Programa Bolsa Família faz uso de características observáveis, o que possibilita a construção de um grupo contrafactual usando as mesmas características do grupo de tratamento. Em outras palavras, podemos usar estratégia de matching para construir um grupo de controle estatisticamente idêntico em características observáveis. 
A primeira hipótese que o modelo de matching precisa respeitar é a de exogeneidade, ou seja, a variável de resultado (distorção idade-série) é exógena ao recebimento do tratamento $(\mathrm{PBF})$ dada uma série de variáveis explicativas $(\mathrm{X})$. Tal hipótese refere-se ao fato de que os grupos de tratamento e de controle se tornam estatisticamente idênticos após o controle por covariadas que definam a participação ou não no tratamento.

$$
Y_{i}(0) \perp T_{i} \mid X_{i}
$$

Em que $Y_{i}$ é a variável de resultado, $T_{i}$ é a variável binária que indica se o indivíduo recebeu ou não o tratamento e $X_{i}$ é um vetor que contém variáveis explicativas quanto ao tratamento.

Outra hipótese de relevância para o pareamento é a de sobreposição, a qual garante que para cada indivíduo tratado haja um par correspondente no grupo de controle com características observáveis semelhantes. Posto de outra forma, a região do vetor de variáveis determinantes ao tratamento deve representar tanto o grupo de tratamento quanto o grupo de controle.

$$
\operatorname{pr}\left[T_{i}=1 \mid X_{i}\right]<1
$$

A partir das hipóteses elencadas acima, é possível calcular o efeito médio do tratamento sobre os tratados (ATT), que se dá através da diferença do indivíduo que recebe o tratamento e seu resultado, caso não recebesse:

$$
A T T=E\left[Y_{i}(1) \mid T_{i}=1, X\right]-E\left[Y_{i}(0) \mid T_{i}=1, X\right]
$$

Em que $E\left[Y_{i}(1) \mid T_{i}=1, X\right]$ é a esperança de $Y$ para a população dos tratados, dado um vetor de características observáveis $X$, e $E\left[Y_{i}(0) \mid T_{i}=1, X\right]$ é a esperança de $\mathrm{Y}$ para o grupo dos tratados, caso não houvesse o tratamento.

Não é possível, no entanto, observar $E\left[Y_{i}(0) \mid T_{i}=1, X\right]$ na equação (3), conforme supracitado. A hipótese de independência garante que:

$E\left[Y_{i}(0) \mid T_{i}=1, X\right]=E\left[Y_{i}(0) \mid X\right]=E\left[Y_{i}(0) \mid T_{i}=0, X\right]=E\left[Y_{i} \mid T_{i}=0, X\right]$

Dada a equação $(4)^{7}$, é possível calcular o ATT através da equação (5):

7 A hipótese da independência condicional garante que, condicionado a um conjunto de variáveis explicativas, o tratamento seja independente do resultado potencial, assim sendo, o grupo de controle prediz bem o grupo de tratamento na ausência dele (Resende; Oliveira, 2008). 


$$
E A T T=E\left[Y_{i} \mid T_{i}=1, X\right]-E\left[Y_{i} \mid T_{i}=0, X\right]
$$

O efeito médio do tratamento sobre os tratados é possível a partir da diferença média de Y entre o grupo de tratamento e o grupo de controle condicionado à presença do tratamento $\left(T_{i}=1\right)$. É praticável reescrever a equação (5) tirando a esperança, dado que houve o tratamento:

$$
A T T=E\left[E\left[Y_{i} \mid T_{i}=1, X\right]-E\left[Y_{i} \mid T_{i}=0, X\right] \mid T_{i}=1\right]
$$

Quando há um grande número de covariadas, o pareamento exato torna-se quase impossível, e esse problema chama-se Maldição da Dimensionalidade. Para evita-lo, Rosenbaum e Rubin (1983) sugerem um modelo denominado na literatura de Propensity Score Matching, no qual o vetor $\mathrm{X}$ deixa de ser utilizado para definir o tratamento, o qual passa a ser definido por uma função de X que sintetiza toda a informação contida em tal vetor. A função probabilidade de receber o tratamento pode ser descrita por:

$$
p(X)=\operatorname{pr}[T=1 \mid X]
$$

A hipótese de ortogonalidade passa a ser:

$$
Y_{i}(0) \perp T_{i} \mid p\left(X_{i}\right)
$$

O estudo propõe estimar a propensão ao tratamento por meio de um modelo logístico (Logit). A probabilidade de participação no Programa Bolsa Família é dada por:

$$
\operatorname{Pr}\left[T_{i}=1 \mid X\right]=[\exp (x \beta)] /[1+\exp (x \beta)]
$$

E o estimador:

$$
\hat{\mathrm{p}}(\mathrm{x})=[\exp (x \hat{\beta})] /[1+\exp (x \hat{\beta})]
$$

Por fim, calcularemos o ATT - efeito médio do tratamento sobre os tratados - através do estimador da equação (10):

$$
A T T=E_{p(x) \mid T=1} E\left[Y_{i}(1) \mid T=1, p(x)\right]-E\left[Y_{i}(0) \mid T=0, p(x)\right]
$$


Para a construção dos matching optamos por utilizar diversos algoritmos, a saber: vizinho mais próximo e cinco vizinhos mais próximos com reposição - os tratados serão comparados com os controles de características mais próximas e a reposição garante aos indivíduos do grupo de controle que sejam comparados com mais de um indivíduo do grupo de tratamento; radius em que cada indivíduo do grupo de tratamento é comparado com observações dentro de um raio de distância (o calliper utilizado é de 0,01); e Kernel em que o indivíduo do grupo de tratamento é comparado a uma média ponderada de indivíduos do grupo de tratamento e a ponderação dá-se pela proximidade de características.

Utilizar diversos algoritmos ajuda a entender melhor o real efeito de uma variável sobre a outra, uma vez que a escolha de apenas um algoritmo necessariamente implicará na escolha do trade-off de viés e de variância. Por exemplo, o modelo de vizinho mais próximo com reposição garante que o indivíduo do grupo de tratamento seja comparado ao indivíduo mais semelhante a ele no grupo de controle, restringindo o viés, mas a redução na quantidade de indivíduos total no grupo de controle causa um aumento da variância (Caliendo; Kopeinig, 2008). Caliendo e Kopeinig (2008) também ressaltam que o modelo de Kernel pode usar todos os indivíduos do grupo de controle para formar o contrafactual, por meio de médias ponderadas. No entanto, apesar de redução da variância por utilizar muitas observações no grupo de controle, o viés pode crescer na medida em que são utilizados indivíduos do grupo de controle que não correspondem ao indivíduo do grupo de tratamento.

\subsubsection{Análise de Sensibilidade}

O teste de sensibilidade é fundamental para verificar se há omissão de alguma variável relevante que afete fazer parte do grupo que recebe Bolsa Família (tratamento) (Cunha et al., 2013; Moreira et al., 2016)" O chamado viés de variável omitida pode ser testado pelo procedimento conhecido por Limites de Rosenbaum (Rosenbaum, 2002).

Segundo Rosenbaum (2002), a probabilidade de receber o tratamento (beneficiário do Bolsa Família) do indivíduo $i$ é dada por:

$$
\pi_{i}=\operatorname{Pr}\left(T_{i}=1 \mid X_{i}\right)=F\left(\beta X_{i}+\gamma \varepsilon_{i}\right)
$$


Em que $\pi_{i}$ é a probabilidade de o indivíduo ser do grupo de tratamento, dado um conjunto de covariadas observáveis $X_{i}$. O efeito do erro não observável sobre o indivíduo que recebe o tratamento $\left(T_{i}=1\right)$ é dado por $\gamma$.

Quando há ausência de viés, $\gamma=0$, a probabilidade de fazer parte do grupo de tratamento é dada apenas pelas covariadas observadas. Em uma função com distribuição logística $\mathrm{F}($.$) , com dois indivíduos pareados, i$ e $j$, com probabilidades relativas de recebimento do tratamento dadas, respectivamente, por $\frac{\pi_{i}}{1-\pi_{i}} \mathrm{e} \frac{\pi_{j}}{1-\pi_{j}}$,

a razão de probabilidades é dada na equação (13):

$$
\frac{\pi_{i} /\left(1-\pi_{i}\right)}{\pi_{j} /\left(1-\pi_{j}\right)}=\frac{e^{\left(\beta X_{i}+\gamma \varepsilon_{i}\right)}}{e^{\left(\beta X_{j}+\gamma \varepsilon_{j}\right)}}=e^{\gamma\left(\varepsilon_{i}-\varepsilon_{j}\right)^{8}}
$$

A equação acima mostra que a razão será igual a 1 quando não houver variáveis omitidas afetando a probabilidade do tratamento $\gamma=0$. Quando esta razão for diferente de l, há uma importante variável sendo omitida. Os Limites de Rosenbaum consistem, de maneira simples, em entender como as variáveis omitidas afetam a diferença dada por $\varepsilon_{i}-\varepsilon_{j}$.

\subsection{Variáveis}

A variável de resultado foi construída de maneira distinta para o tipo de ensino fundamental: quando o ingresso foi no ensino fundamental de 8 anos, o cálculo da distorção é adaptado e feito de acordo com Ribeiro e Cacciamali (2012), em que $\mathrm{x}$ assume 7; para o caso de ensino fundamental de 9 anos, x assume 6 , conforme a equação $(14)^{9}$ a seguir:

$$
D_{i}=\left\{\begin{array}{l}
0 \text { se } \frac{\text { Ano Escolar }}{\text { Idade }_{i, t}-x} \geq 1 \\
1 \text { se } \frac{\text { Ano Escolar }}{\text { Idade }_{i, t}-x}<1
\end{array}, \forall x \neq 6 \text { ou } 7\right.
$$

8 Por pressuposto do pareamento, $\beta X_{i}=\beta X_{j}$, logo, estes valores se anulam.

9 Aqui ressaltamos que nossa amostra possui alunos que estão matriculados no ensino fundamental com 9 níveis e alunos que estão matriculados no currículo antigo, em que o ensino fundamental possui apenas 8 níveis. Essa distinção é importante, pois a idade inicial muda de uma estrutura para outra, com nove níveis a idade inicial do aluno é 6 anos, e na estrutura com 8 níveis a idade inicial do aluno é 7 anos. 
Em que: Ano Escolar representa o nível escolar em que aluno está matriculado (varia do $1^{\circ}$ ao $9^{\circ}$ ano escolar); $I_{d a d e}$ é a idade do aluno i no ano $t$, e $x$ é a idade inicial definida na estrutura curricular do ensino fundamental, ou seja, é a idade adequada para que o aluno comece o ensino fundamental. Na estrutura atual do ensino fundamental essa idade é de 6 anos. Assim, será considerado distorção na idade-série o aluno que estiver fora da idade adequada.

O Quadro 1 apresenta a descrição, a média e o desvio-padrão de cada uma das covariadas utilizadas, da variável de tratamento (PBF) e da variável de resultado (distorção idade-série) no agregado de todos os anos A média de pessoas que estão em distorção idade-série é de 22,92\%, enquanto $2,55 \%$ das pessoas recebem auxílio do Bolsa-Família.

Quanto à renda líquida, ela é de aproximadamente 100 reais por pessoa - excluindo o valor recebido no $\mathrm{PBF}$-, a amostra é maior de meninos $(50,65 \%)$, aproximadamente $80 \%$ dos estudantes autodeclaram-se não brancos, $48,43 \%$ estão em zona urbana e $21,13 \%$ em alguma região metropolitana.

Quadro 1 - Estatísticas Descritivas

\begin{tabular}{|l|l|l|l|}
\hline Variáveis & Descrição & Média & DP1 \\
\hline Distorção idade-série & Assume 1 para quem está distorcido e 0 caso contrário & $22,92 \%$ & 0,42 \\
\hline PBF & Recebeu o benefício do programa atribui valor igual a 1 e 0 caso contrário. & $2,55 \%$ & 0,16 \\
\hline Renda líquida & Renda per capita domiciliar descontado o valor recebido do programa. & 99,50 & 74 \\
\hline Gênero & Assume valor 1 para mulher e 0 caso contrário. & $49,35 \%$ & 0,5 \\
\hline Raça & Assume valor 1 para branca ou amarela e 0 caso contrário. & $20,59 \%$ & 0,4 \\
\hline Urbano & Assume valor 1 para morador de zona urbana e 0 caso contrário. & $48,43 \%$ & 0,5 \\
\hline Metropolitano & Assume valor 1 para moradores de região metropolitana e 0 caso contrário. & $21,13 \%$ & 0,41 \\
\hline Nível de Instrução mais Elevado no Domicílio & & \\
\hline Sem estudos & Assume 1 para quem tem menos de 1 ano de educação e 0 caso contrário & $13,91 \%$ & 0,34 \\
\hline Fund. Incompleto & Assume 1 para quem tem fundamental incompleto e 0 caso contrário & $66,44 \%$ & 0,47 \\
\hline Fundamental Completo & Assume 1 para quem tem fundamental completo e 0 caso contrário & $16,88 \%$ & 0,37 \\
\hline Médio Completo & Assume 1 para quem tem médio completo e 0 caso contrário & $2,56 \%$ & 0,16 \\
\hline Superior Completo & Assume 1 para quem tem médio completo e 0 caso contrário & $0,21 \%$ & 0,06 \\
\hline & \multicolumn{1}{|c|}{ Observações } & 119.797 \\
\hline
\end{tabular}

Fonte: Elaboração própria

Nota: ${ }^{1}$ Desvio-Padrão. 
Quanto à escolaridade máxima no domicílio, apenas 2,77\% possuem pelo menos ensino médio completo, e acima de $80 \%$ não completaram o ensino fundamental e não estudaram. Sendo o ensino fundamental a escolaridade máxima alcançada, a porcentagem é de $16,88 \%$.

\section{Resultados}

O objetivo foi investigar os efeitos do PBF na distorção idade-série, nos anos entre 2016 e 2019, e encontrar a existência de possíveis heterogeneidades em função do gênero, das regiões brasileiras e dos anos estudados. Alguns trabalhos encontraram o impacto positivo do programa no desempenho, na matrícula e no combate ao abandono escolar (Amaral; Monteiro, 2013; Araújo et al., 2015; Camargo; Pazello, 2014; De Brauw et al., 2015; Glewwe; Kassouf, 2012; Neto, 2010) porém, o trabalho de Ribeiro e Cacciamali (2012) não encontrou efeito estatisticamente significativo do programa sobre a distorção idade-série. A presente seção apresenta os resultados aqui encontrados, em que todas as estimações consideraram controles descritos no Quadro 1, além de controles para ano da pesquisa e para Unidade Federativa.

A Tabela abaixo mostra os resultados do modelo Propensity Score Matching para os diversos métodos de pareamento testados, em que NR (1) é o vizinho mais próximo, NR (5) são os cinco vizinhos mais próximos, radius e Kernel. As colunas estão divididas entre a amostra completa, meninos e meninas. 
Tabela 1 - Resultados do Bolsa Família sobre a distorção idade-série entre 2016 e 2019

\begin{tabular}{lccc}
\hline & Todos & Meninos & Meninas \\
\hline NR (1) com reposição & $-0,0223^{* * *}$ & $-0,0440^{* *}$ & $-0,0274^{* * *}$ \\
& $(0,0086)$ & $(0,0259)$ & $(0,009)$ \\
NR (5) com reposição & $-0,0283^{* * *}$ & $-0,0399^{*}$ & $-0,0307^{* * \star}$ \\
& $(0,0068)$ & $(0,0214)$ & $(0,006)$ \\
Radius & $-0,0305^{* * *}$ & $-0,0562^{* * *}$ & $-0,0307^{* * *}$ \\
& $(0,006)$ & $(0,020)$ & $(0,006)$ \\
Kernel & $-0,0602^{* * *}$ & $-0,0722^{* * *}$ & $-0,0458^{* \star *}$ \\
& $(0,006)$ & $(0,0194)$ & $(0,006)$ \\
\hline
\end{tabular}

Fonte: Elaboração própria

Nota: erros-padrão entre parênteses. ${ }^{* * *} \mathrm{p}<0,01 ;{ }^{* *} \mathrm{p}<0,05 ;{ }^{*} \mathrm{p}<0,10$.

O resultado para os dados empilhados mostra uma queda entre 2,23 p.p e 6,02 p.p na distorção de alunos que são beneficiários do Bolsa Família. Tal resultado difere do que é encontrado em Ribeiro e Cacciamali (2012), que não atribui evidências de impactos do $\mathrm{PBF}$ na distorção idade-série. $\mathrm{A}$ diferença obtida pode ser explicada pelo fato de os dados das autoras serem de 2006 e o Programa Bolsa-Família ter sido implementado por lei em janeiro de 2004 (a partir de uma medida provisória de outubro de 2003), ou seja, em pouco tempo de programa, o efeito sobre a distorção poderia ainda não ter sido estatisticamente significativo, uma vez que um estudante é considerado distorcido com 2 ou mais anos de atraso escolar. Cabe salientar que os resultados diferem-se de acordo com o algoritmo utilizado, pois, segundo Caliendo e Kopeinig (2008), diferentes algoritmos produzem resultados com menor variância ou menor viés, já que a metodologia de escolha do grupo de controle é diferente em cada um dos algoritmos.

É possível observar que no método dos 5 vizinhos mais próximos o resultado da amostra total é inferior aos demais resultados, o que é possível uma vez que a amostra é maior quando unificados meninos e meninas, e o pareamento pode encontrar outros indivíduos do grupo de controle para parear com o grupo de tratamento, de modo que o resultado da amostra como um todo não é, necessariamente, uma média ponderada entre meninos e meninas. 
Os resultados para os meninos são significativos e indicam uma redução na distorção idade-série variando entre 3,99 p.p e 7,22 p.p. Já para as meninas, os resultados variam menos, sendo entre 2,74 p.p e 4,58 p.p. Destacamos que a média de distorção idade-série entre os meninos é de $26,94 \%$, enquanto para as meninas é de $18,79 \%$.

A nossa variável dependente, a distorção idade-série, pode ser explicada por alguns motivos diferentes: a reprovação, o aluno ter abandonado a escola e depois voltar, e o início tardio. Já a variável de tratamento, receber o $\mathrm{PBF}$, exige que os beneficiários se mantenham na escola, então o efeito na redução da distorção idade-série pode andar por dois caminhos: o primeiro é o fato de entrar na escola na idade certa e evitar o abandono escolar, uma vez que para receber o benefício, há a necessidade da frequência escolar; o outro é pelo custo de oportunidade de o aluno estar na sala de aula e não ser aprovado.

A Tabela 2 apresenta os resultados dos Limites de Rosenbaum em que a hipótese nula é que há viés oriundo de variável omitida - não observável ou não controlada. Esse teste de sensibilidade transmite informações importantes sobre como o nível de incerteza envolvido nos estimadores afetará as conclusões das análises de amostragem correspondentes. Os resultados mostram que no total e para as meninas é possível rejeitar a $1 \%$ de significância a hipótese nula. Não há evidências que alguma variável não observável afete o tratamento e os resultados.

Contudo, para os meninos, ao atingir um valor para 'I de 1,5 não significa que não se observará o efeito positivo do programa sobre a redução da distorção idade-série. Este resultado mostra que - em caso do viés de seleção para a participação no programa for diferente em razão de chances por um fator de 1,5, quando comparados grupo tratamento e controle - o intervalo de confiança para o efeito do tratamento passará por zero (Diprete; Gangl, 2004; Resende; Oliveira, 2008). 
Tabela 2 - Limites de Rosenbaum

\begin{tabular}{lllllc}
\hline & Total & \multicolumn{2}{c}{ Meninos } & \multicolumn{2}{c}{ Meninas } \\
\hline $\mathbf{I}$ & P-Valor & 'I & P-Valor & ' & P-Valor \\
\hline 1,0 & 0,0000 & 1,0 & 0,0000 & 1,0 & 0,0000 \\
1,05 & 0,0000 & 1,05 & 0,0000 & 1,05 & 0,0000 \\
1,10 & 0,0000 & 1,10 & 0,0001 & 1,10 & 0,0000 \\
1,15 & 0,0000 & 1,15 & 0,0005 & 1,15 & 0,0000 \\
1,20 & 0,0000 & 1,20 & 0,0016 & 1,20 & 0,0000 \\
1,25 & 0,0000 & 1,25 & 0,0044 & 1,25 & 0,0000 \\
1,30 & 0,0000 & 1,30 & 0,0105 & 1,30 & 0,0000 \\
1,35 & 0,0000 & 1,35 & 0,0223 & 1,35 & 0,0000 \\
1,40 & 0,0000 & 1,40 & 0,0417 & 1,40 & 0,0000 \\
1,45 & 0,0000 & 1,45 & 0,0744 & 1,45 & 0,0001 \\
1,50 & 0,0000 & 1,50 & 0,1196 & 1,50 & 0,0005 \\
\hline
\end{tabular}

Fonte: Elaborado pelos autores

Além do teste de sensibilidade (Tabela 2), realizamos um teste de falseamento, que é apresentado no apêndice - Tabela A2. A variável dependente foi o mês de nascimento do estudante e em nenhum dos meses do ano houve efeito do PBF, indicando robustez nos resultados apresentados na Tabela 1. Para demonstrar a efetividade do pareamento para redução de viés, a Tabela 3 apresenta o viés médio e o viés mediano antes e depois dos pareamentos, além de um teste de máxima verossimilhança (LR Chi²) entre os grupos.

Tabela 3 - Mudança no viés por causa do pareamento (Dados empilhados para os anos de 2016 a 2019).

\begin{tabular}{lllllll}
\hline & & Pseudo $\mathrm{R}^{2}$ & LR Chi & P-Valor & Média Viés & Mediana Viés \\
\hline Total & Antes & 0,105 & 2984.33 & 0,000 & 8,6 & 3,2 \\
& Depois & 0,002 & 25,6 & 0,938 & 1,6 & 1,4 \\
\multirow{2}{*}{ Meninos } & Antes & 0,016 & 83,21 & 0,000 & 12,6 & 10,8 \\
& Depois & 0,002 & 2,75 & 0,987 & 2,9 & 1,7 \\
\multirow{2}{*}{ Meninas } & Antes & 0,052 & 1119,08 & 0,000 & 14,3 & 4,8 \\
& Depois & 0,001 & 6,10 & 0,866 & 1,6 & 1,5 \\
\hline
\end{tabular}

Fonte: Elaborado pelos autores 
A Tabela 3 mostra que o pareamento é eficiente em reduzir as diferenças entre os grupos. O viés médio e o viés mediano reduzem-se em todas as amostras testadas. O teste de $\mathrm{LR} \mathrm{Chi}^{2}$ antes dos pareamentos indicava rejeição da hipótese nula de igualdade entre os grupos, enquanto após o pareamento não é possível rejeitar tal hipótese. Outra forma de identificar a qualidade do pareamento é através da análise gráfica da densidade de Kernel entre os grupos, conforme apresentado nas Figuras A1, A2 e A3 do apêndice A. Em tais figuras, os grupos de tratados e controles possuem densidades muito distintas, mas após o pareamento elas se tornam semelhantes. Apesar dos testes mostrarem que não há evidências dos grupos serem diferentes, a Tabela A2 mostra que mesmo com algumas variáveis estatisticamente diferentes entre os grupos antes do pareamento, após o pareamento esta diferença desaparece.

O resultado da Tabela 1 apresenta significância no efeito geral do Brasil, mas dadas as características regionais, esses efeitos podem ser diferentes para cada região do país. Nas Figuras 1 e 2 essa observação fica um pouco mais clara, uma vez que as características de distorção idade-série e transferência do Bolsa Família são diferentes no Brasil, porém, são mais semelhantes dentro das regiões. A literatura destaca que há heterogeneidade entre as regiões, assim sendo, a estimação de resultados por região - conforme a Tabela 4 - garante a obtenção de resultados mais robustos (Chitolina, Foguel e Menezes-Filho, 2016; Ribeiro, Shikida e Hillbrecht, 2017).

A Tabela 4 apresenta os efeitos do PBF sobre a distorção idade-série nas cinco regiões brasileiras. Destacamos que o Sul não apresenta efeito significativo, entretanto, nas demais regiões os efeitos variam entre a redução de 4,72 p.p. na região Norte e a redução de 11,1 p.p. no Centro-Oeste; a região Sudeste tem uma redução de 5,59 p.p. na distorção idade-série e a região Nordeste, 6,94 p.p. Cabe salientar que a região Norte, que apresenta maior proporção de alunos defasados, tem a menor redução de distorção por parte do PBF. 
Tabela 4 - Resultados do Bolsa Família sobe a distorção idade-série escolar por Regiões (Dados empilhados para os anos de 2016 a 2019).

\begin{tabular}{ccccc}
\hline Norte & Nordeste & Sudeste & Sul & Centro-Oeste \\
\hline$-0.0472^{* * *}$ & $-0.0694^{* * *}$ & $-0.0559^{* * *}$ & -0.000301 & $-0.111^{* * *}$ \\
$(0.0121)$ & $(0.008)$ & $(0.0191)$ & $(0.0335)$ & $(0.0213)$ \\
\hline
\end{tabular}

Fonte: Elaboração Própria

Nota: Regressão utilizando o método de Kernel com replicações bootstrap. ${ }^{* * *} \mathrm{p}<0,01 ;{ }^{* *} \mathrm{p}<0,05$; ${ }^{*} \mathrm{p}<0,10$.

A Tabela 5, com os resultados separados por ano, mostra que os beneficiários do Bolsa Família possuem, em média, menos distorção idade-série que seus pares sem o benefício, ao longo do período analisado, no Brasil. Com isso, é possível perceber que o efeito do PBF de redução sobre a distorção idade-série varia de 5,04 p.p., em 2019, a 8,10 p.p, em 2017.

Tabela 5 - Resultados do Bolsa Família sobe a distorção idade-série escolar por ano

\begin{tabular}{cccc}
\hline 2016 & 2017 & 2018 & 2019 \\
\hline$-0.0680^{* * *}$ & $-0.0810^{\star * *}$ & $-0.0542^{\star \star *}$ & $-0.0504^{* \star *}$ \\
$(0.0105)$ & $(0.01)$ & $(0.011)$ & $(0.0122)$ \\
\hline
\end{tabular}

Fonte: Elaboração Própria

Nota: Regressão utilizando o método de Kernel com replicações bootstrap. ${ }^{* * *} \mathrm{p}<0,01 ;{ }^{* *} \mathrm{p}<0,05$; ${ }^{*} \mathrm{p}<0,10$.

\section{Considerações finais}

Desde a sua implantação, o Programa Bolsa Família vem sendo tema importante nos debates políticos e acadêmicos. De forma recorrente, pesquisas na área de economia buscam avaliar os efeitos do programa (Cavalcanti et al., 2016; Chitolina; Foguel; Menezes-Filho, 2016; Reynolds, 2015; Simões; Sabates, 2014). O trabalho de Ribeiro, Shikida e Hillbrecht (2017) levantou um conjunto de pesquisas indicando que, em alguns pontos, o 
PBF ainda não possui evidências suficientes para conclusão. Dessa forma, além do nosso trabalho contribuir marginalmente com esse debate, nós também tratamos o impacto do programa sobre a distorção idade-série, tema discutido apenas por Ribeiro e Cacciamali (2012).

O estudo apresenta novas evidências em relação ao trabalho de Ribeiro e Cacciamali (2012), e nossos resultados, estimados pela Propensity Score Matching (PSM), mostram que o Programa Bolsa Família gera os efeitos positivos esperados ao reduzir a distorção idade-série no Brasil. Desta forma, essa pesquisa se une aos trabalhos que majoritariamente concluem acerca dos efeitos positivos do Bolsa Família sobre os indicadores educacionais e abre mais espaços para a discussão a respeito dos efeitos com base na distorção idade-série.

É possível observar que a região Centro-Oeste foi a que obteve o melhor resultado no combate à distorção idade-série com o Programa Bolsa Família, já para a região Sul, o PBF não apresentou efeito significativo sobre a distorção idade-série. Em todos os anos da amostra houve redução da distorção idade-série. Para pesquisas futuras, a questão das disparidades intrarregionais fica em aberto, podendo ser abordada com mais precisão utilizando dados municipais - com o uso do Censo Demográfico - ou estaduais - com o uso de PNADs mais recentes. Outro ponto importante refere-se à pandemia da Covid-19 que, com a suspensão das aulas presenciais, pode ter afetado a distorção, principalmente, para alunos da rede pública. 


\section{Referências}

Amaral, E. F. L. e Monteiro, V. P. 2013. "Avaliação de impacto das condicionalidades de educação do Programa Bolsa Família (2005 e 2009)”. Dados, v. 56, no. 3: 531-570.

Araújo, F. R. et al. 2015. "Uma avaliação do Índice de Gestão Descentralizada do Programa Bolsa Família". Revista de Administração Pública, v. 49. no. 2: 367-393.

Araújo, G. S., Ribeiro, R. e Neder, H. D. 2010. "Impactos do Programa Bolsa Família sobre o trabalho de crianças e adolescentes residentes na área urbana em 2006". Revista Economia, v. 11. no. 4: 57-102.

Becker, G. S. e Tomes, N. 1979. "An equilibrium theory of the distribution of income and intergenerational mobility". Journal of Political Economy, v. 87. no. 6: 1153-1189.

Bissoli, A. C. S. 2007. "Evasão escolar: o caso do colégio estadual Antônio Francisco Lisboa". Maringá - SEAP. Acesso feito em: 25 de janeiro de 2020 http://www.repositorio.seap.pr.gov.br/arquivos/file/artigos/educaçao/ evasao_escolar.pdf

Caliendo, M. e Kopeinig, S. 2008. "Some practical guidance for the implementation of propensity score matching" Journal of Economic Surveys, v. 22, no. 1: 31-72.

Camargo, P. C. e Pazello, E. T. 2014.”Uma análise do efeito do Programa Bolsa Família sobre o desempenho médio das escolas brasileiras". Economia Aplicada, v. 18, no. 4: 623-640.

Cavalcanti, D. M. et al. 2016. "Impacts of Bolsa Família Programme on income and working offer of the poor famílies: an approach using the treatment of quantile effect". Economia Aplicada, v. 20, no. 2: 173.

Cechin, L. A. W. et al. 2015. "O impacto das regras do Programa Bolsa Família sobre a fecundidade das beneficiárias”. Revista Brasileira de Economia, v. 69, no. 3: 303-329.

Chitolina, L., Foguel, M. N. e Menezes Filho, N. A. 2016. "The impact of the expansion of the Bolsa Família Program on the time allocation of youths and their parents". Revista Brasileira de Economia, v. 70, no. 2.

Cunha, D. A. et al. 2013.”'Irrigação como estratégia de adaptação de pequenos agricultores às mudanças climáticas: aspectos econômicos". Revista de Economia e Sociologia Rural, v. 51, no. 2: 369-386.

De Brauw, A. et al. 2015. "The impact of Bolsa Família on schooling". World Development, v. 70: 303-316.

Diprete, T. A. e Gangl, M. 2004. "Assessing Bias in the estimation of causal effects: Rosenbaum Bounds on matching estimators and instrumental variables estimation with imperfect instruments". Sociological Methodo$\log y$, v. 34, no. 1: 271-310.

Ferreira, S. G. e Veloso, F. A. 2003. "Mobilidade intergeracional de educação no Brasil". Pesquisa e Planejamento Econômico, v. 33, no. 3: 481-513.

Glewwe, P. e Kassouf, A. L. 2012. "The impact of the Bolsa Escola/Familia conditional cash transfer program on enrollment, dropout rates and grade promotion in Brazil". Journal of Development Economics, v. 97, no. 2: $505-517$.

Hanushek, E. A. e Woessmann, L. 2008. "The role of cognitive skills in economic developmen”t. Journal of economic literature, v. 46, no. 3: 607-668.

Machado, D. C. e Gonzaga, G. 2007. "O impacto dos fatores familiares sobre a defasagem idade-série de crianças no Brasil”. Revista Brasileira de Economia, v. 61, no. 4: 449-476.

Mazumder, B. 2005. "Fortunate sons: new estimates of intergenerational mobility in the United States using social security earnings data". The Review of Economics and Statistics, v. 87, no. 2: 235-255.

Moreira, G. C. et al. 2016. "Programa Bolsa Família e violência doméstica contra a mulher no Brasil". Estudos Econômicos, v. 46, no. 4: 973-1002.

Myrdal, G. 1975. "The equality issue in world development". The Swedish Journal of Economics, v. 77, no. 4: 413-432. 
Nascimento, A. R. e Kassouf, A. L. 2016. "Impacto do Programa Bolsa Família sobre as decisões de trabalho das crianças: uma análise utilizando os microdados da PNAD”. Análise Econômica, v. 34, no. 66.

Neto, R. M. S. 2010. "Impacto do programa Bolsa Família sobre a frequência à escola: estimativas a partir de informações da Pesquisa Nacional por Amostra de Domicílio (PNAD)". Bolsa Família 2003-2010: avanços e desafios, v. 2: 53. Castro, J. A.; Modesto, L. (Orgs.). IPEA. Brasília.

Resende, A. C. C. e Oliveira, A. M. H. C. 2008. "Avaliando resultados de um programa de transferência de renda: o impacto do Bolsa-Escola sobre os gastos das famílias brasileiras". Estudos Econômicos, v. 38, no. 2: 235-265.

Reynolds, S. A. 2015. "Brazil's Bolsa Familia: does it work for adolescents and do they work less for it?" Economics of Education Review, v. 46: 23-38.

Ribeiro, F. G., Shikida, C. e Hillbrecht, R. 2017. "O. Bolsa Família: um survey sobre os efeitos do programa de transferência de renda condicionada do Brasil”. Estudos Econômicos, v. 47, no. 4: 805-862.

Ribeiro, R. e Cacciamali, M. C. 2012. "Impactos do Programa Bolsa-Família sobre os indicadores educacionais". Revista Economia, v. 13, no. 2: 415-446.

Rosenbaum, P. R. 2002. "Observational studies" Observational studies, Springer. p. 1-17.

Rosenbaum, P. R. e Rubin, D. B. 1983. "The central role of the propensity score in observational studies for causal effects". Biometrika, v. 70, no. 1: 41-55.

Santarrosa, R. B. 2011. "Impacto das Transferências Condicionadas de Renda sobre a proficiência dos alunos do Ensino Fundamental no Brasil". Fundação Getúlio Vargas.

Simões, A. A. e Sabates, R. 2014. "The contribution of Bolsa Família to the educational achievement of economically disadvantaged children in Brazil”. International Journal of Educational Development, v. 39: 141-156.

Simões, P. e Soares, R. B. 2012. "Efeitos do Programa Bolsa Família na fecundidade das beneficiárias". Revista Brasileira de Economia, v. 66, no. 4: 445-468.

Soares, F. V. 2010. "Para onde caminham os programas de transferência condicionada ? As experiências comparadas do Brasil, México, Chile e Uruguai”. Bolsa Família 2003-2010: avanços e desafio, v.2: p. 137-168. Castro, J. A.; Modesto, L. (Orgs.). IPEA. Brasília..

Soares, S. et al. 2007. "Programas de transferência condicionada de renda no Brasil, Chile e México: impactos sobre a desigualdade" Texto para Discussão: 1293. Instituto de Pesquisa Econômica Aplicada - IPEA, Acesso feito em: 10 de outubro de 2019. https://www.ipea.gov.br/portal/images/stories/PDFs/TDs/td_1293.pdf.

Souza, A. P. 2011. "Políticas de distribuição de renda no Brasil e o Bolsa Família". C-Micro Working Paper Series. Fundação Getúlio Vargas - São Paulo. 


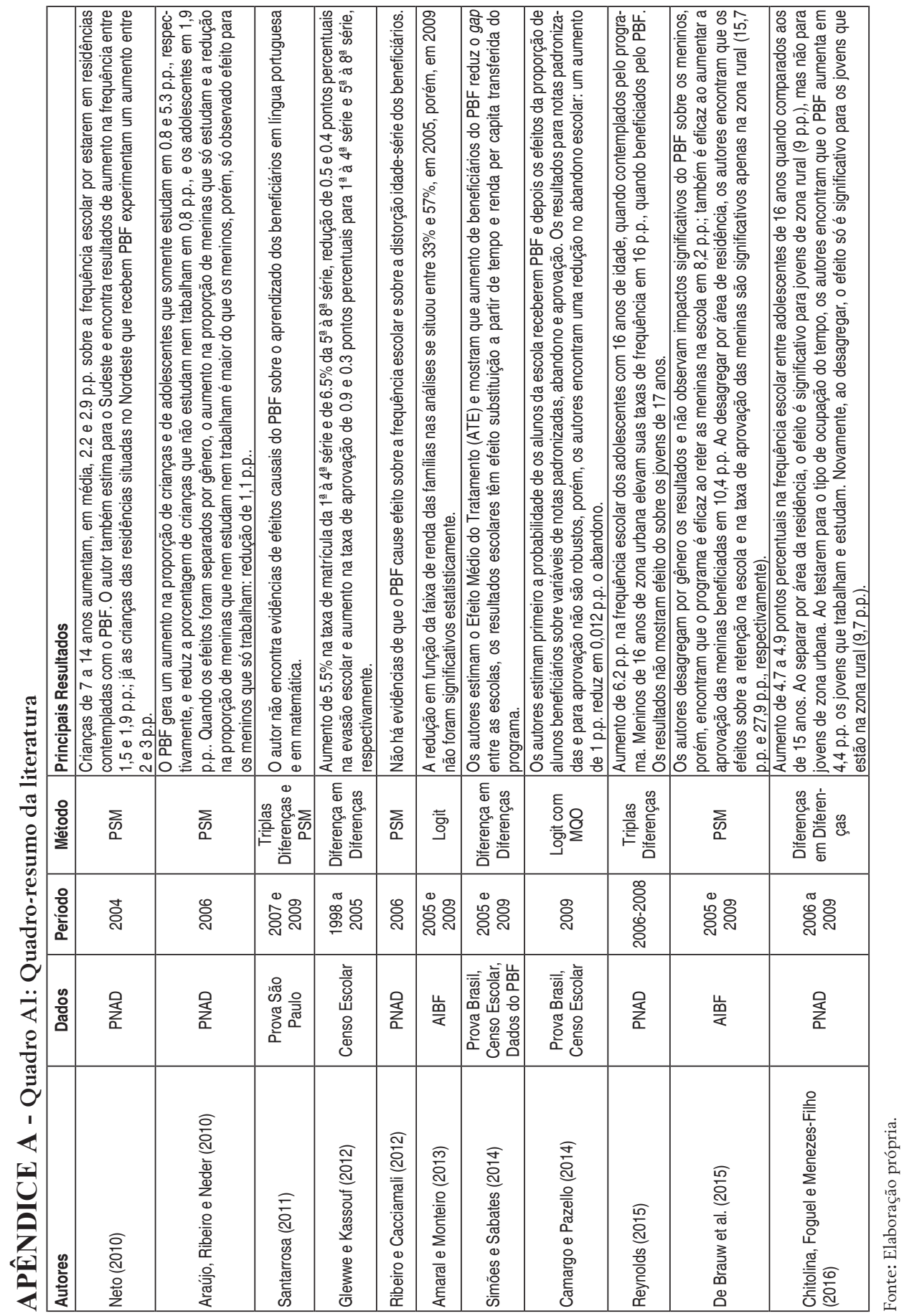



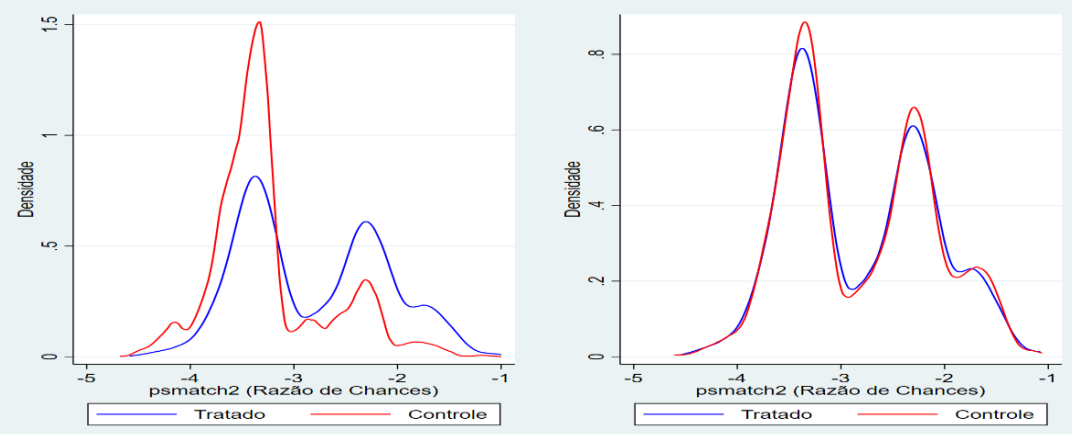

Figura Al - Pareamento da Amostra Total

Fonte: Elaboração própria
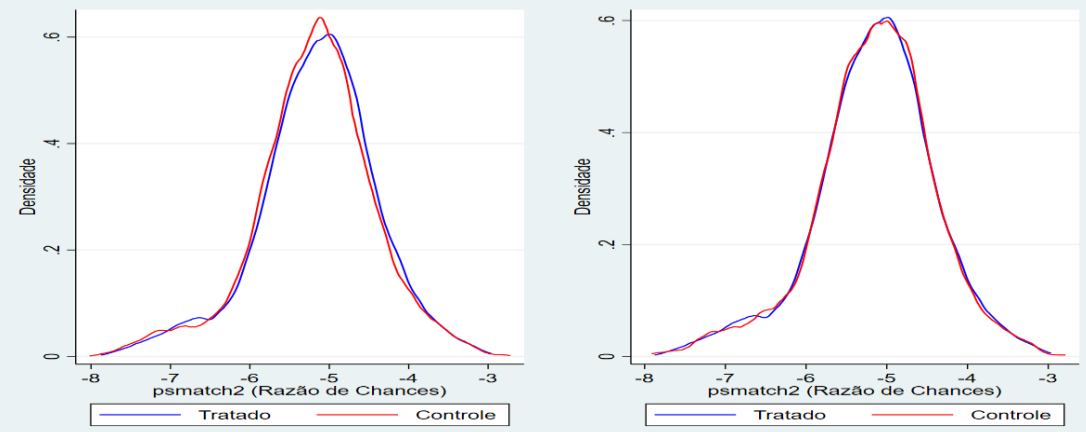

Figura A2 - Pareamento da Amostra Meninos

Fonte: Elaboração própria
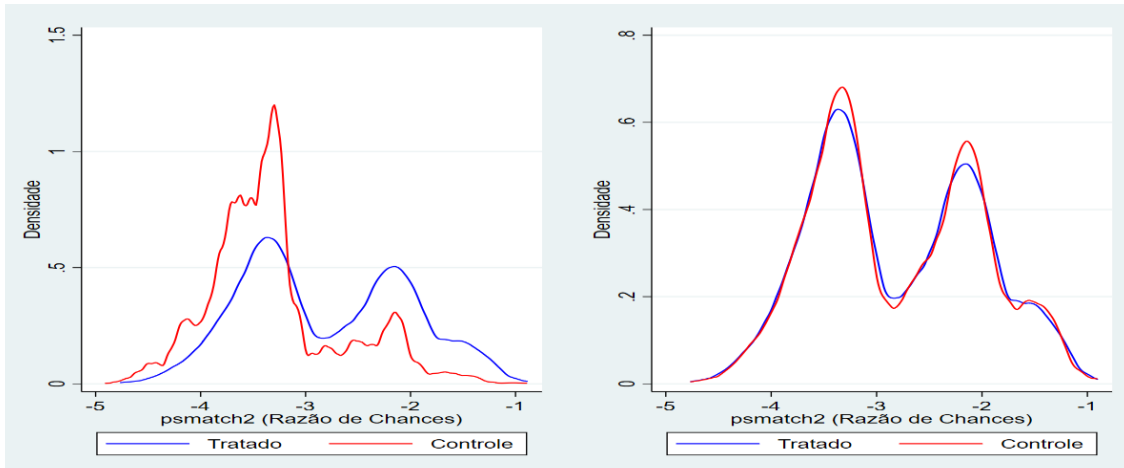

Figura A3 - Pareamento da Amostra Meninas

Fonte: Elaboração própria 
Tabela Al - Teste de Placebo: Resultados do Bolsa Família sobre o mês de nascimento

\begin{tabular}{|c|c|c|c|}
\hline \multirow{2}{*}{ Janeiro } & 0,00149 & \multirow{2}{*}{ Julho } & 0,00222 \\
\hline & $(0,00519)$ & & $(0,00546)$ \\
\hline \multirow{2}{*}{ Fevereiro } & $-0,00636$ & \multirow{2}{*}{ Agosto } & 0,00234 \\
\hline & $(0,00423)$ & & $(0,00559)$ \\
\hline \multirow{2}{*}{ Março } & 0,00317 & \multirow{2}{*}{ Setembro } & 0,00737 \\
\hline & $(0,00536)$ & & $(0,00536)$ \\
\hline \multirow{2}{*}{ Abril } & 0,00213 & \multirow{2}{*}{ Outubro } & $-0,00265$ \\
\hline & $(0,00438)$ & & $(0,00473)$ \\
\hline \multirow{2}{*}{ Maio } & 0,00256 & \multirow{2}{*}{ Novembro } & $-0,00136$ \\
\hline & $(0,00540)$ & & $(0,00499)$ \\
\hline \multirow{2}{*}{ Junho } & 0,000331 & \multirow{2}{*}{ Dezembro } & $-0,00229$ \\
\hline & $(0,00489)$ & & $(0,00478)$ \\
\hline \multicolumn{2}{|c|}{ Observações } & \multicolumn{2}{|c|}{119.797} \\
\hline
\end{tabular}

Fonte: Elaboração própria 


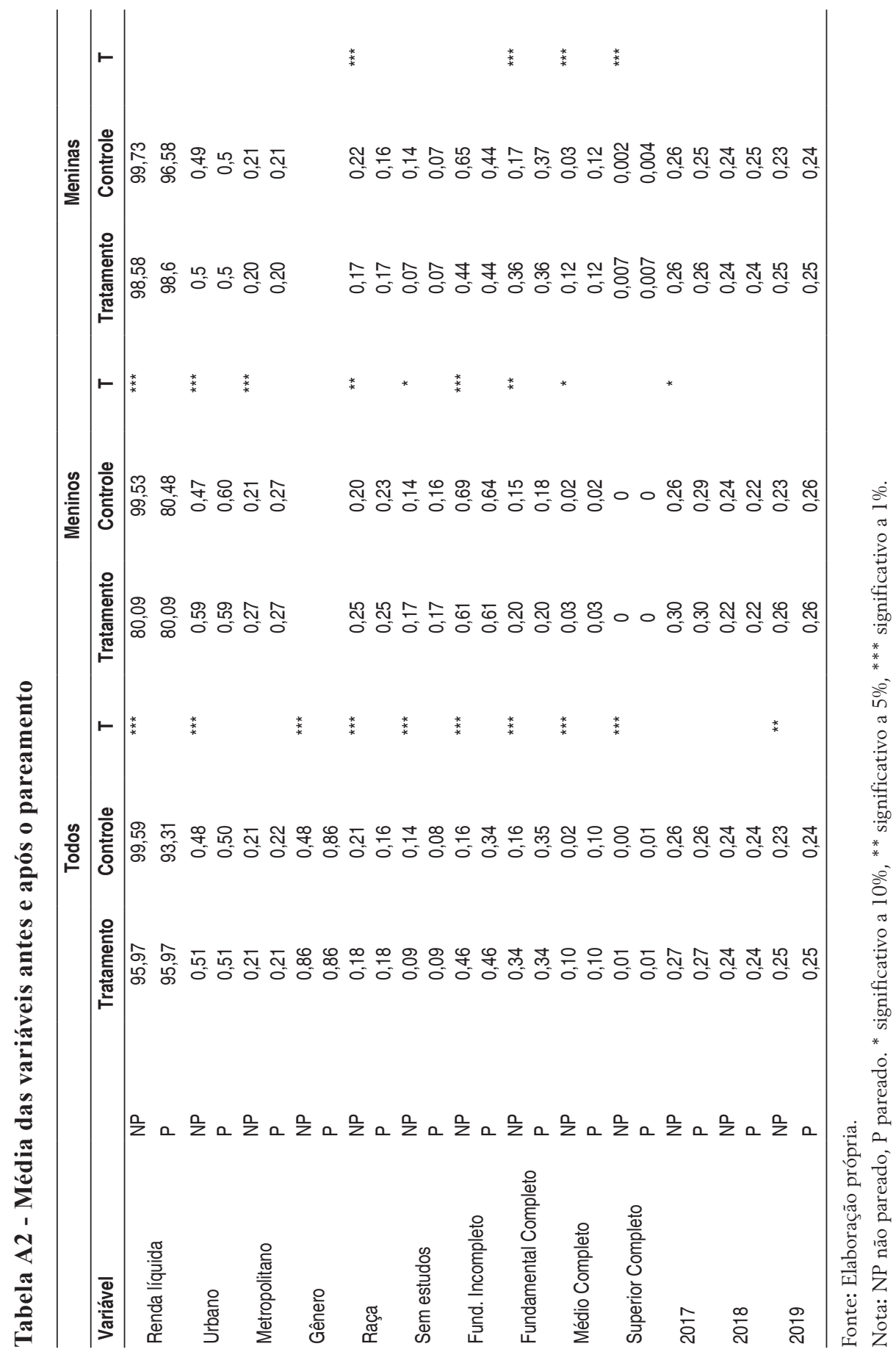

